\title{
Female gender is not a proven risk factor for depression in glioma
}

\author{
Alasdair G. Rooney · David van Nieuwenhuizen • \\ Jacob C. Reijneveld · Robin Grant
}

Received: 26 May 2009/Accepted: 19 June 2009/Published online: 21 July 2009

(C) Springer Science+Business Media, LLC. 2009

\section{To the Editor:}

We read Litofsky and Resnick's timely and useful review of depression in brain tumour patients with interest [1]. The authors identified screening for depression as an issue requiring future study. Because screening is often targeted at high-risk groups, it is important to study the risk factors for depression in brain tumour patients.

The authors state that female gender is a risk factor for depression in glioma. It is true that some groups have found women with brain tumours to be more likely than men to become depressed [2, 3]. However other researchers have not, including one of the authors of the review [4-6].

We sent a questionnaire to the GP of each glioma patient on our hospital database (Edinburgh, UK), asking whether their patient had suffered depression both before and since the diagnosis of glioma. The diagnosis of depression was based on the clinical judgement of each GP. Response rate was $68 \%$ (100/147; 55\% male). A pre-glioma (past medical) history of depression was significantly more likely in women (12/45 women compared with 3/55 men; $P=0.004$, Fisher's Exact Test). However following glioma presentation the sex difference in depression disappeared and men were equally as likely as women to experience depression (12/55 and 12/45 respectively; $P=0.64)$.

Female gender is not a proven risk factor for depression in glioma. Since general population surveys consistently

\footnotetext{
A. G. Rooney $(\bowtie) \cdot$ R. Grant

Western General Hospital, Edinburgh, UK

e-mail: a.rooney@nhs.net

D. van Nieuwenhuizen $\cdot$ J. C. Reijneveld

VU Medisch Centrum, Amsterdam, Netherlands
}

report that depression is twice as common in women [7], studies reporting a more equal sex distribution for depression in brain tumours may even suggest a relatively increased risk for men.

We agree that depression in glioma is a fertile field for research. For now we suggest that men and women with glioma should be considered at equal risk of developing depression, and that efforts should therefore be made to include them equally in any proposed screening programmes.

\section{References}

1. Litofsky NS, Resnick AG (2009) The relationships between depression and brain tumours. J Neurooncol. doi:10.1007/s11060009-9825-4

2. Arnold SD, Forman LM, Brigidi BD, Carter KE, Schweitzer HA, Quinn HE et al (2008) Evaluation and characterization of generalized anxiety and depression in patients with primary brain tumors. Neuro-oncology 10:171-181

3. D'Angelo C, Mirijello A, Leggio L, Ferrulli A, Carotenuto V, Icolaro $\mathrm{N}$ et al (2008) State and trait anxiety and depression in patients with primary brain tumors before and after surgery: 1-year longitudinal study. J Neurosurg 108:281-286

4. Kilbride L, Smith G, Grant R (2007) The frequency and cause of anxiety and depression amongst patients with malignant brain tumours between surgery and radiotherapy. J Neurooncol 84:297304

5. Mainio A, Hakko H, Niemela A, Koivukangas J, Rasanen P (2006) Gender difference in relation to depression and quality of life among patients with a primary brain tumour. Eur Psychiatry 21:194-199

6. Litofsky NS, Farace E, Anderson F, Meyers CA, Huang W, Laws ER et al (2004) Depression in patients with high grade glioma: results of the glioma outcomes project. Neurosurgery 54:358-367

7. Piccinelli M, Homen FG (1997) Gender differences in the epidemiology of affective disorders and schizophrenia. World Health Organisation, Geneva 